\title{
A DANÇA NA PRÁTICA PEDAGÓGICA COM CRIANÇAS: OLHARES E REFLEXÕES DE UMA PROFESSORA EM FORMAÇÃ̃
}

\author{
Patricia Taborda Galvão ${ }^{\mathrm{i}}$ \\ Daiana Camargo ${ }^{\text {ii }}$
}

\begin{abstract}
Resumo: As reflexões apresentadas neste texto abordam a dança na prática pedagógica na Educação Infantil, a partir do olhar de uma acadêmica de Pedagogia e bailarina. A vivência com a dança possibilitou indagações e inquietações que instigaram a pesquisa. Escritos da área da dança, da educação física, da pedagogia e da arte nos amparam a tratar a dança na escola. Para compreendermos aspectos da dança na prática pedagógica, o estudo contou com a participação de professoras de Educação Infantil e profissionais da área da dança. É possível apontar a desvinculação da dança de outros conteúdos (ou temas) da prática pedagógica, a relação dança/desenvolvimento motor em detrimento de uma perspectiva mais ampla, expressiva, lúdica e cultural e a ausência de reflexão e/ou fundamentação sobre corpo e o movimento. Ressaltamos a necessidade de que a dança, e toda a sua dimensão cultural e lúdica, possa integrar os espaços de formação de professores de crianças, aqui em específico a Pedagogia, para que possamos questionar, refletir os sentidos e possibilidades do corpo em movimento, para que outras propostas possam ser desenvolvidas a partir da dança nos espaços educativos, com maior sentido e significado.
\end{abstract}

Palavras-chave: Corpo e movimento; Dança; Criança; Educação infantil.

\section{LA DANZA EN LA PRÁCTICA PEDAGÓGICA CON NIÑOS: MIRADAS Y REFLEXIONES DE UNA PROFESORA EN FORMACIÓN}

Resumen: Las reflexiones presentadas en este texto abordan la danza en la práctica pedagógica en el jardín de infantes, desde la mirada de una alumna de pedagogía y bailarina. La experiencia con la danza generó preguntas y preocupaciones que motivaron la investigación. Textos de danza, educación física, pedagogía y arte nos ayudan a tratar la danza en la escuela. Para comprender aspectos de la danza en la práctica pedagógica, el estudio contó con la participación de maestros de preescolar y profesionales de la danza. Los datos se obtuvieron mediante cuestionario, posteriormente fueron tratados con el software Iramuteq, y analizados con la función de nube de palabras. Es posible señalar la desvinculación de la danza de otros contenidos (o temas) de la práctica pedagógica, la relación danza/desarrollo motor en detrimento de una perspectiva más amplia, expresiva, lúdica y cultural y ausencia de reflexión y/o fundamentación sobre el cuerpo y el movimiento. Enfatizamos la necesidad de que la danza (cuerpo y movimiento) integre los espacios de formación de maestros de niños para romper la dicotomía cuerpo y mente.

Palabras clave: Cuerpo y movimiento; Danza; Niño; Educación Infantil. 


\title{
DANCE IN PEDAGOGICAL PRACTICE WITH CHILDREN: LOOKS AND REFLECTIONS OF A TRAINEE TEACHER
}

\begin{abstract}
The reflections introduced in this text address dance in pedagogical practice in kindergarten, from the perspective of a student of pedagogy and dancer. The experience with dance generated questions and concerns that motivated the investigation. Texts of dance, physical education, pedagogy and art help us to treat dance in school. To understand aspects of dance in pedagogical practice, the study was attended by preschool teachers and dance professionals. The data were obtained through a questionnaire, treated subsequently with the Iramuteq software, and analyzed with the word cloud function. It is possible to point out the dissociation of the dance from other contents (or themes) of the pedagogical practice, the relationship dance / motor development to the detriment of a broader, expressive, playful and cultural perspective and lack of reflection and / or foundation on the body And the movement. We emphasize the need for dance (body and movement) to integrate children's teacher training spaces to break the body and mind dichotomy.
\end{abstract}

Keywords: Body and movement; Dance; Child; Early Childhood education.

\section{Os primeiros passos...}

Este texto apresenta reflexões sobre a dança e a prática pedagógica na Educação Infantil. A prática de uma das autoras como professora de ballet marca profundamente a escolha do tema de pesquisa. Por meio da realização do Estágio Curricular do Curso de Pedagogia em instituições de Educação Infantil foi possível perceber que a dança e demais propostas que envolvam corpo e movimento são pouco abordadas nos espaços educativos. Destas experiências vieram as inquietações e a necessidade de compreender como a dança pode ser inserida na Educação Infantil, de uma forma que proporcione a criança pequena contribuições para o desenvolvimento integral, para a compreensão da cultura e da diversidade.

Assim, nos dedicamos a um estudo sobre as contribuições da dança para a criança pequena, bem como as possibilidades do trabalho com a dança, tendo um olhar direcionado para se compreender o conhecimento que as professoras de crianças pequenas têm sobre a dança na Educação Infantil.

Consideramos que historicamente o corpo é negligenciado nos espaços educativos, cujo enfoque recai sobre o controle dos movimentos, o domínio dos impulsos e a docilização, em prol da produção. Assim, consideramos que os espaços de formação de professores podem se constituir como espaço para pensar outras formas de atuação, espaço de criação e de resistência, em prol de uma criança essencialmente movimento. 
Como referencial teórico para a pesquisa nos amparamos tanto nas produções específicas da área de dança, quanto da educação física, da arte e da Pedagogia. Vale destacar que no âmbito da Pedagogia ainda são poucos os escritos que remetem a corpo e movimento, ainda mais na especificidade da dança. Sigamos.... Outros passos

\section{Brincar, mover-se, dançar.}

Para dançar, é preciso mover-se, e quanto mais espontâneo esse movimento for, mais ele transmite uma linguagem que vem de dentro para fora, expressando sentimentos, emoções, conhecimentos e experiências. Com isso, se faz necessário possibilitar que a criança desde bem pequena possa explorar seus movimentos através da dança, sem que essa dança seja de forma restritiva e cansativa, é preciso pensar em possibilidades de um trabalho com a dança de uma maneira diferenciada, levando para elas uma dança nova, diferente do que temos presenciado e da qual temos ouvido falar ao nos inserirmos nas instituições educativas de crianças, cujo enfoque recai sobre datas comemorativas e danças distantes das possibilidades e interesses de crianças pequenas. Ainda é comum que as danças apareçam nas instituições educativas apenas nos festejos, como algo a ser exibido aos pais e a comunidade, por vezes sem sentido para a criança. Ao olharmos para as possibilidades, trazemos a dança como parte do cotidiano, da dança circular, das cantigas de roda, dos jogos de bate mão... E avançamos pensando nas crianças como participantes das decisões sobre o que se dança e como se dança.

Deste modo, é importante proporcionar momentos de dança para as crianças de maneira lúdica. Sobre isso diz Almeida (2016, p.61):

A adoção da ludicidade como um recurso pedagógico para mediar a dança na educação infantil demonstra-se motivadora devido ao seu caráter dinâmico, criativo e atraente. Esse universo de alegria e prazer do lúdico envolve os jogos, brinquedos e brincadeiras.

Por meio da ludicidade o trabalho com a dança acontece de maneira mais eficiente quando se pensa em alcançar e atrair o sujeito que dela participará, a criança. Com a ludicidade a dança se torna mais atraente para a criança, adquirindo um caráter dinâmico, fazendo com que as possibilidades do trabalho com a dança sejam mais criativas e divertidas dentro das escolas. 
Autores como Almeida (2016), Marques (2012) e Capri (2015), defendem que as brincadeiras e os jogos auxiliam no trabalho com a dança, pois ambos contribuem para a construção e para a ampliação do movimento. A partir das brincadeiras a criança também adquire conhecimento sobre o seu corpo, as partes que o compõe, sua postura, permitindo que elas tomem conhecimento sobre o corpo, espaço e movimento. Assim como a dança, o brincar contribui para a tomada de decisões, expressão de desejos, opiniões e sentimentos, a comunicação com outro, e a aprendem sobre como funcionam as regras, e como devem se posicionar diante delas (ALMEIDA, 2016).

Brincar e dançar, ambos possibilitam muitos benefícios para as crianças, possuindo muitos objetivos em comum, e com isso, se faz possível vincular este trabalho, pensando em atividades lúdicas. De acordo com Almeida (2016, p.65) brincar é criar vínculos e possibilita estabelecer relações. Ao propiciarmos situações lúdicas, de jogo, estamos estimulando a constituição de vínculos e a educação de pessoas sensíveis ao olhar e ao diálogo.

A junção do brincar com a dança estimula a criança a gostar de participar de tais atividades, porque para ela o dançar se torna um momento único e divertido, por isso quando um professor planeja uma atividade com dança ele precisa pensar na criança, porque essa criança precisa amar estar envolvida nessa atividade com a dança. Marques (2012, p.35), destaca que:

É primordial pensarmos a dança na escola também como uma dança lúdica, que brinca, que permite e incentiva relações - e não imposições. A ludicidade nas propostas de dança permite que vínculos sejam recriados, ou seja, que experiências sejam possibilitas, descobertas incentivadas, recombinações realizadas.

As brincadeiras contribuem no trabalho com a dança, auxiliando no desenvolvimento motor, como já descrito neste trabalho, a criança quer e deseja estar em constante movimento, e com isso pensar em brincadeiras que possibilitem a elas o movimento, contribuirá diretamente em seu desenvolvimento motor, além de proporcionar a elas momentos lúdicos, os quais elas participarão de maneira prazerosa, sem que sejam forçadas e obrigadas a estarem nesses momentos.

A criança aprende brincando, e através das brincadeiras há muitas possibilidades de se trabalhar com a dança, Capri (2015, p.290) afirma que: 
A ludicidade faz parte do universo infantil, e permitir o lúdico não descaracteriza a dança. A criança brinca e aprende brincando. $\mathrm{O}$ trabalho lúdico em propostas de dança na educação infantil possibilita novas relações, e não imposições.

O trabalho com a dança precisa ser aberto a novas possibilidades, é preciso que os professores deixem aquilo que é rotineiro e engessado (as mesmas cantigas, os mesmos movimentos, os restrito gestos) e pensem em práticas inovadoras no que se refere a dança na educação infantil, e para isso se faz necessário usufruir da ludicidade, sendo que ela oferece um grande suporte para planejar atividades diferenciadas, propostas nas quais a criança interaja com o seu eu, com o outro, se movimente e tenha liberdade ao mover-se.

Porém, é preciso que os professores estejam preparados e dispostos a buscarem por mais criatividade, visto que hoje se tem diversos recursos que podem auxiliar neste processo. $\mathrm{O}$ entendimento da criança enquanto ser social, criança ativa e protagonista é fundamental neste contexto, para que o professor considere suas potencialidades de intervenção e criação. Outro elemento a considerar é o entendimento que se tem de como a criança aprende e se expressa, pois ao falarmos de dança falamos de corpos que se movimentam, experimentam, produzem sons, se agitam e se acalmam e é preciso ressaltar que a instituição educativa tende a restringir o movimento, numa perspectiva de dominação e docilização, como destaca Foucault (2007).

Além do trabalho com dança de maneira lúdica, se é muito importante que os professores utilizem diferentes espaços da escola para a realização das atividades, é preciso explorar os ambientes que há na escola, uma vez que esses espaços favorecem a interação entre as crianças e com o professor (GARANHANI, 2015). A música também é uma grande aliada nesse processo. Botelho (S/D), afirma que:

É a partir do movimento que podemos perceber as primeiras realizações das crianças e a manifestação do desenvolvimento do sistema perceptivosensório-motor. O movimento e a música caminham juntos e se completam um com o outro. Dança sem música e ouvir música e não se movimentar é quase que impossível, pois as ligações dos nervos auditivos estão largamente espalhadas pelo nosso corpo e são mais longas que quaisquer outros nervos.

A criança desde o ventre materno tem contanto com a música, ela tem contato com tudo que sua mãe ouve durante a gestação. Desta forma, ressaltamos a importância do trabalho com os sons, a exploração de diferentes instrumentos e objetos, a exploração dos 
sons produzidos no corpo e com o corpo, o contato com diferentes músicas e a apreciação do silencio, instigando os movimentos rápidos e lentos, leves e fortes, exploração de tempo e espaço, manifestação de diferentes sentimentos e emoções, sensações...

Assim, compreende-se que são grandes as possibilidades para a efetivação do trabalho com a dança na educação infantil, e nos faz perceber a importância que esse trabalho tem para o desenvolvimento da criança pequena. Garanhani $(2015$, p.188) ressalta que que é por meio do movimento do seu corpo que a criança pequena compreende os significados presentes no meio cultural em que ela está inserida, e com isso compreendemos o quanto relevante é o trabalho com o movimento na educação infantil.

As crianças que estão presentes nos dias de hoje nas escolas, anseiam para que os professores olhem para elas, olhem para o desejo que elas têm de serem vistas como criança, elas estão desejando por brincar, mover-se e dançar.

No decorrer deste trabalho foi possível compreender a importância que a dança tem no processo de ensino e aprendizagem e no desenvolvimento motor da criança, visto que ela proporciona muitos benefícios à criança pequena quando esta tem contato com a dança frequentemente, e um dos espaços mais importantes que podem possibilitar esse contato da criança com a dança é a escola.

\section{A dança nos documentos norteadores da Educação Infantil}

A dança precisa estar presente na Educação Infantil para efetivar suas finalidades e objetivos discutidos anteriormente e com isso se fez necessário uma análise nos documentos norteadores da Educação Infantil para analisar se eles propõem o trabalho com o corpo e movimento, e em específico sobre a dança, uma vez que, esses documentos norteiam todo o trabalho com as crianças da Educação Infantil, de modo que, os mesmos eixos e conteúdos sejam trabalhados em diferentes escolas, independentemente da localidade.

Segundo Buss-Simão (2016, p.185):

"[...] as crianças, nesse momento de suas vidas, vivenciam o mundo, constroem conhecimentos, expressam-se, interagem e manifestam desejos e curiosidades de modo bastante peculiar. Essa concepção requer que as ações educativas sejam intencionalmente planejadas e permanentemente observadas, registradas e avaliadas; requer também que as ações educativas 
considerem a integridade e indissociabilidade das dimensões expressivomotora, afetiva, cognitiva, linguística, ética, estética e sociocultural das crianças".

As atividades que envolvem a dança precisam ser bem planejadas pelos educadores, não podem ser atividades soltas, sem intencionalidade pedagógica. Deste modo, é possível perceber a importância que os documentos norteadores têm para a realização de tais atividades, uma vez que nas Diretrizes Curriculares Nacionais para a Educação Infantil (DCNEIs) é defendido o brincar e a interação como eixos norteadores do trabalho pedagógico, bem como destaca os princípios éticos, estéticos e políticos. Os princípios estéticos garantem a valorização da sensibilidade, da criatividade, da ludicidade e da diversidade de manifestações artísticas e culturais (2010, p.7), contemplando assim as possibilidades de trabalho envolvendo o corpo e o movimento, o brincar e a dança.

Na Base Nacional Comum Curricular - BNCC (2017), a organização curricular da Educação Infantil estrutura os eixos estruturantes em cinco campos de experiências, sendo eles: o eu, o outro e nós; corpo gestos e movimentos; escuta, fala, pensamento e imaginação; traços sons, cores e imagens; espaços, tempos, quantidades, relações e transformações. (BRASIL, 2017). De acordo com Buss-Simão (2016, p. 196)

Os Campos de Experiência constituem-se como uma forma de organização curricular que busca compreender que a educação e o cuidado das crianças, desde bebês, devem estar centrados nas interações e nas brincadeiras, das quais emergem as linguagens, as observações, os questionamentos, as investigações e outras ações das crianças articuladas com a proposições trazidas pelas professoras e professores. Cada um deles oferece às crianças a oportunidade de estabelecer ações e relações com as pessoas, tempos, objetos, situações e atribuir um sentido pessoal e social a eles.

Os Campos de Experiência têm por objetivo proporcionar a criança uma aprendizagem significativa, por meio das experiências que ela já possui consigo e das experiências que ela ainda irá adquirir com as atividades. A partir dos Campos de Experiência é possível pensar em atividades mais lúdicas e mais significativas para as crianças, fazer com que o trabalho com o corpo e movimento possa ser construído cotidianamente, com sentido e significado, amparado nas possibilidades das crianças, dos interesses, da cultura e da valorização da diversidade. No que se refere ao trabalho com o corpo, a BNCC apresenta: 
Corpo, gestos e movimentos - Com o corpo (por meio dos sentidos, gestos, movimentos impulsivos ou intencionais, coordenados ou espontâneos), as crianças, desde cedo, exploram o mundo, o espaço. Conteúdo em discussão no CNE. Texto em revisão. E os objetos do seu entorno, estabelecem relações, expressam-se, brincam e produzem conhecimentos sobre si, sobre o outro, sobre o universo social e cultural, tornando-se, progressivamente, conscientes dessa corporeidade. Por meio das diferentes linguagens, como a música, a dança, o teatro, as brincadeiras de faz de conta, elas se comunicam e se expressam no entrelaçamento entre corpo, emoção e linguagem[...] (BRASIL, 2017).

Dessa forma, é possível perceber que o trabalho com a dança está presente na BNCC, de modo que este trabalho venha a ser cada vez mais explorado pelos professores. No Campo de Experiência corpo, gestos e movimento são elencados alguns objetivos de aprendizagem e desenvolvimento, sendo referente a dança (BRASIL, 2017, p. 43):

- Movimentar as partes do corpo para exprimir corporalmente emoções, necessidades e desejos.

- Criar com o corpo formas diversificadas de expressão de sentimentos, sensações e emoções, tanto nas situações do cotidiano quanto em brincadeiras, dança, teatro, música.

- Explorar formas de deslocamento no espaço (pular, saltar, dançar), combinando movimentos e seguindo orientações.

- Criar movimentos, gestos, olhares e mímicas em brincadeiras, jogos e atividades artísticas como dança, teatro e música.

Proporcionar experiências significativas para as crianças, permite que ela passe por diversos desafios relacionados ao conhecer seu corpo, e com isso os professores devem estar atentos as necessidades da criança que envolvem essas experiências, procurando atividades que efetivem esse trabalho, sempre observando que os documentos propõem para essa efetivação (BUSS-SIMÃO, 2016).

Nas DCNEIs (Figura 5), a proposta curricular deve ter como eixo as interações e brincadeiras, e essas propostas estão presentes neste documento, no Art. $9^{\circ}$ :

FIGURA 5: Art. $9^{\circ}$ das DCNEIs 
Art. $9^{\circ}$ As práticas pedagógicas que compõem a proposta curricular da Educação Infantil devem ter como eixos norteadores as interações e a brincadeira, garantindo experiências que:

I - promovam o conhecimento de si e do mundo por meio da ampliação de experiências sensoriais, expressivas, corporais que possibilitem movimentação ampla, expressão da individualidade e respeito pelos ritmos e desejos da criança;

II - favoreçam a imersão das crianças nas diferentes linguagens e o progressivo domínio por elas de vários gêneros e formas de expressão: gestual, verbal, plástica, dramática e musical;

III - possibilitem às crianças experiências de narrativas, de apreciação e interação com a linguagem oral e escrita, e convívio com diferentes suportes e gêneros textuais orais e escritos;

IV - recriem, em contextos significativos para as crianças, relações quantitativas, medidas, formas e orientações espaçotemporais;

V - ampliem a confiança e a participação das crianças nas atividades individuais e coletivas;

VI - possibilitem situações de aprendizagem mediadas para a elaboração da autonomia das crianças nas ações de cuidado pessoal, auto-organização, saúde e bem-estar;

VII - possibilitem vivências éticas e estéticas com outras crianças e grupos culturais $s_{2}$ que alarguem seus padrões de referência e de identidades no diálogo e reconhecimento da diversidade;

VIII - incentivem a curiosidade, a exploração, o encantamento, o questionamento, a indagação e o conhecimento das crianças em relação ao mundo físico e social, ao tempo e à natureza;

IX - promovam o relacionamento e a interação das crianças com diversificadas manifestações de música, artes plásticas e gráficas, cinema, fotografia, dança, teatro, poesia e literatura;

$\mathrm{X}$ - promovam a interação, o cuidado, a preservação e o conhecimento da biodiversidade e da sustentabilidade da vida na Terra, assim como o não desperdício dos recursos naturais;

XI - propiciem a interação e o conhecimento pelas crianças das manifestações e tradições culturais brasileiras;

XII - possibilitem a utilização de gravadores, projetores, computadores, máquinas fotográficas, e outros recursos tecnológicos e midiáticos.

FONTE: Diretrizes Curriculares Nacionais para a Educação Infantil-2013

Observando os objetivos presentes nestes documentos norteadores, foi possível compreender que a dança contempla todos os objetivos neles propostos, atividades com dança possibilita que a criança conheça a si e o outro, interaja com as demais crianças, desenvolva variados movimentos, e alcance os demais objetivos propostos nos documentos. Finco (2015, p.237) afirma que:

Tomar a criança como ponto de partida, compreender que, para ela, conhecer o mundo envolve o afeto, o prazer e o desprazer, a fantasia, o brincar e o movimento, a poesia, as ciências, as artes plásticas e dramáticas, a linguagem a música e a matemática.

Esses documentos valorizam o trabalho com o movimento, eles propõem uma pedagogia voltada para a criança como sujeito da aprendizagem, uma pedagogia pensada para a criança, e isso é essencial para que os professores repensem em suas práticas docentes, uma vez que, o trabalho com o corpo, movimento e dança está proposto nos documentos como conteúdo a serem efetivados em sala de aula. 


\section{Olhando para a Educação Infantil: a pesquisa}

Para dar continuidade no encaminhamento da pesquisa, se fez necessário o contato com os Centros Municipais de Educação Infantil (CMEIs), os quais são responsáveis pelo atendimento de crianças com faixa etária de 0 a 5 anos. A escolha dessa faixa etária se deu pelo motivo de que é entre esse período que acontece o desenvolvimento motor da criança, e se inicia o processo do desenvolvimento cognitivo desta.

Na pequena infância o corpo em movimento constitui a matriz básica, em que se desenvolvem as significações do aprender, devido ao fato de que a criança transforma em símbolo aquilo que pode experimentar corporalmente e seu pensamento se constrói, primeiramente, sob a forma de ação. (GARANHANI, 2015, P.90)

Adentramos dois Centros Municipais de Educação Infantil para a realização da pesquisa, no intuito de compreender o que as professoras pensam e sabem sobre a dança. Optamos por um encontro de apresentação da pesquisa e pela aplicação de questionários, tendo em vista a demanda de trabalho em ambas as instituições 1 .

A escolha dos CMEIs ocorreu pelo fato de que eles têm sido referências no tanto no trabalho com as crianças quanto na construção de uma gestão democrática e preocupada com a formação permanente.

\section{As participantes da pesquisa: professoras de crianças}

Os sujeitos participantes dessa pesquisa foram 13 (treze) professoras atuantes como docentes nos CMEIs escolhidos, bem como2 (duas) profissionais na área da dança infantil que atuam com crianças pequenas em diferentes espaços a fim de analisar o que elas compreendem sobre a importância da dança no desenvolvimento da criança pequena e como percebem a dança na escola, a partir de sua formação especializada, para que se possa ter uma comparação das respostas e um diálogo entre as diferentes profissionais.

A nomenclatura utilizada para definir os sujeitos da pesquisa foi definida como "Professora" seguido de letras de A a M para os profissionais da Educação Infantil e 
"Especialista" A e B para as professoras de dança, tendo em vista as questões éticas de pesquisa, preservando a identidade dos participantes deste estudo.

Quanto à idade das professoras foi possível identificar que elas possuem idades diferentes e que apenas duas tem a mesma idade ( 29 anos), as demais seguem uma linha entre 23 anos a 47 anos.

No tocante a formação das professoras que participaram desta pesquisa, 3 (três) professoras $(23,1 \%)$ possuem a formação em nível médio - Magistério - formação de docentes, 3 (três) professoras $(23,1 \%)$ possuem a formação em Magistério - formação de docentes + Pedagogia, 5 (cinco) professoras $(38,5 \%)$ possuem a formação somente Pedagogia e 3 (três) professoras $(23,1 \%$ ) possuem uma formação ampliada, sendo Magistério formação de docentes + Pedagogia + Especialização. Dentre 13 professoras apenas 3 (três) tem sua formação somente em Magistério, as demais possuem formação em Pedagogia, assim apontamos a importância de que temas que envolvem corpo e movimento, aqui em específico a dança, sejam contemplados nos cursos de Pedagogia.

Sobre as especialistas, a participante denominada "Especialista A" possui a formação em Educação Física Licenciatura, com especialização em Educação Especial e Inclusiva e em Dança educacional. Já a "Especialista B” possui formação em Educação Física e em Dança, tendo como especialização Mestrado em Educação.

No que se refere ao tempo de atuação das professoras na Educação Infantil, percebe-se que a maioria atuam há bastante tempo nesta área, visto que a professora que tem menos tempo está atuando há 2 anos e 6 meses e a que tem mais tempo atua há 16 anos. De modo geral todas as professoras possuem um tempo significativo de trabalho com crianças pequenas (Figura 9).

FIGURA 9: Tempo de atuação das professoras na Educação Infantil

Tempo de atuação na educação infantil

13 respostas

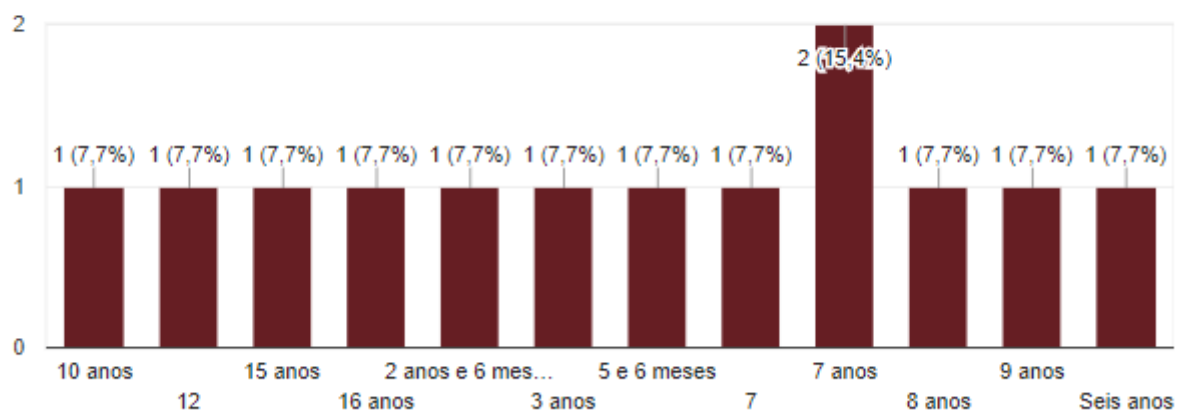

FONTE: Formulário da pesquisa 
De acordo com Garcia (2010), os profissionais docentes constroem sua identidade profissional desde o início de sua formação inicial, e no decorrer dos anos ela se consolida, sendo sujeita a mudanças conforme suas vivências e experiências, essa identidade não surge automaticamente, ela se constrói e se modela, é um processo evolutivo. Sendo assim, o tempo de atuação nas intuições de ensino interfere na construção da identidade profissional do docente, fazendo com que este profissional construa suas concepções e métodos de ensino.

A diferença entre a idade das professoras que participaram desta pesquisa acaba por sua vez interferindo no modo que elas trabalham com seus alunos. Professoras com mais tempo de atuação docente, consequentemente possuem mais experiências do trabalho com crianças pequenas, porém precisam ser flexíveis a possíveis mudanças em seu trabalho devido ao perfil das crianças que adentram nas escolas no decorrer dos anos, buscando sempre se atualizar com formações continuadas. Já professoras iniciantes, possuem menos experiência como docente, sendo necessária a busca por formações que auxiliarão no processo da construção da sua identidade, para que possa assimilar a teoria com a prática, efetivando assim um trabalho significativo para as crianças pequenas.

A identidade profissional é um processo evolutivo de interpretação e reinterpretação de experiências, uma noção que se corresponde com a ideia de que o desenvolvimento do professorado nunca se detém e que se entende como uma aprendizagem ao longo da vida. Partindo desse ponto de vista, a formação da identidade profissional não é a resposta à pergunta "quem sou (neste momento)?", mas sim a resposta à pergunta "o que quero chegar a ser?" (GARCIA, 2010, p.10)

Independentemente do tempo de atuação que uma professora possui, é de extrema importância que esta esteja em constante reflexão sobre sua prática em sala de aula, de modo a permitir que seu aluno seja o sujeito central no processo de aprendizagem, oferecendo-lhe inclusive atividades lúdicas, para que este aluno se desenvolva em todos os aspectos. A pergunta que deve ser feita diariamente é “o que eu quero chegar a ser?", pensando em quais marcas se quer deixar em seus alunos.

\section{Os saberes das professoras de Educação Infantil: o que dizem sobre a dança}

Compreender o que sabem e dizem as professoras participantes dessa pesquisa é fundamental para posteriormente pensarmos as práticas descritas. Os saberes dizem respeito ao conhecimento teórico que tais professoras contêm referente ao tema da pesquisa, que 
foram adquiridos durante a formação inicial e formação continuada. Silva (2009, p.40), aponta que Tardif desvenda em um de seus livros a:

Importância de se compreender como os saberes professorais são constituídos e mobilizados cotidianamente para desempenhar as tarefas subjacentes à ação professoral no ambiente escolar. Em tal perspectiva, o olhar sistematizado reconhece a complexidade da epistemologia da prática docente à luz do sujeito que a constrói.

Assim, olhar para os saberes que as professoras têm sobre o tema desta pesquisa, ampara na compreensão das ações realizadas no ambiente escolar que foram percebidas através de suas respostas.

A fim de compreendermos a dança na prática pedagógica com a criança pequena, indagamos: Em sua formação, você teve aulas que proporcionaram reflexões e práticas sobre a importância da dança para o desenvolvimento da criança? Nessa questão as professoras A, B, C, D, J e K deram como resposta "Não", porém teve três respostas² que exigiu minuciosa observação:

De maneira superficial, mas sim.

(PROFESSORA G)
Algumas aulas
(PROFESSORA L)
Só aulas teóricas.
(PROFESSORA M)

A partir dessas respostas compreende-se que há uma lacuna na graduação do curso de Pedagogia, visto que seria no decorrer da graduação um valioso momento para trabalhar com os acadêmicos sobre a importância do trabalho com o corpo e movimento, em especifico sobre a dança, desvelando as contribuições que dança proporciona para a criança pequena e suas possíveis práticas na escola.

Entretanto, obtivemos duas respostas que chamaram a atenção:

Muito pouco. Porém busco estudar sobre assuntos relacionados ao desenvolvimento infantil e percebo a importância da dança para o desenvolvimento das crianças, desta forma sempre estou inovando e aprimorando minha pratica pedagógica e as crianças retribuem de forma muito positiva e demonstram grande interesse por atividades musicais. (PROFESSORA I) 
Em minha formação tive a disciplina de ritmo e dança. Infelizmente a disciplina não foi totalmente bem aproveitada porque teve falta de professores na universidade. $\mathrm{O}$ pouco que tivemos foi voltado à composição coreográfica e algumas brincadeiras corporais. Faltou muito a questão de discussão sobre dança na escola entre tantos outros saberes relacionados a ela. Mas sempre procurei formações paralelas à universidade. (ESPECIALISTA A)

Percebe-se que a lacuna sobre o conhecimento da importância da dança no desenvolvimento integral da criança pequena, está presente também na graduação de Educação Física Licenciatura que oferece uma disciplina voltada para a dança. A consequência disso acaba sendo quando estes professores se encontram na prática e não sabem como utilizar a dança para o desenvolvimento, aprendizagem e bem-estar das crianças, e não compreendem as possibilidades do trabalho tal eixo.

Entretanto essas respostas mostram que devido à dança ser trabalhada de forma muito sucinta nos cursos de formação de professores, ainda há professores que refletem sobre sua prática e buscam por formações que possam auxiliá-los no trabalhado lúdico com a dança, voltada para a aprendizagem da criança pequena. Desse modo, é muito importante que a reflexão acompanhe a ação dos professores que estão frente às crianças, uma vez que ela mobiliza este docente a buscar novas estratégias de trabalho com os pequenos, refletindo sobre sua prática no sentido de avaliá-la, compreendê-la, modificá-la e ressignificá-la. (GARANHANI, 2015).

Ao indagarmos sobre a importância da dança na prática pedagógica com crianças é possível perceber que algumas professoras possuem um conhecimento sobre a dança de maneira muito superficial, elas compreendem que a dança contribui no desenvolvimento psicomotor, porém sem um conceito maior de expressão, uma fundamentação de sua resposta.

Por meio do software Iramutec foi possível obter os seguintes dados, conforme representado na Figura 10: 
FIGURA 10: A importância da dança na prática pedagógica

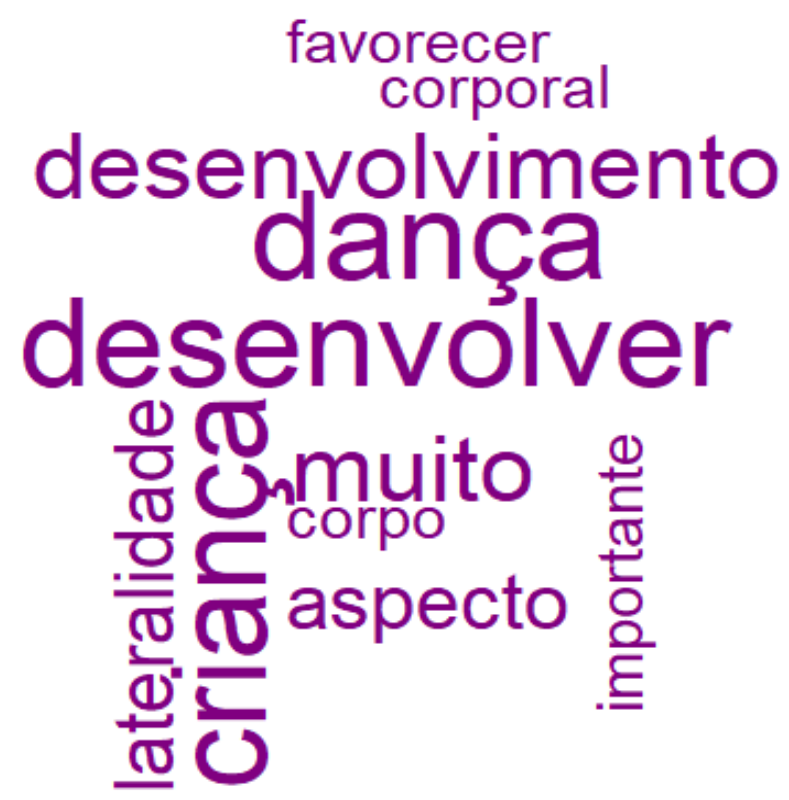

FONTE: Software Iramutec

A nuvem de palavras apresenta a organização dos termos de acordo com a recorrência das mesmas nas respostas das participantes da pesquisa, de modo que as palavras são classificadas pelo tamanho/intensidade de cor. Desse modo pode-se perceber que as palavras que mais apareceram nas respostas foram: desenvolver, criança e dança. Sobretudo, observando a nuvem de palavras como um todo, é possível detectar a dança compreendida como contribuição apenas para o desenvolvimento motor, percebe-se assim uma lacuna no conhecimento sobre as contribuições da dança para a criança pequena, limitando a uma função, o desenvolvimento.

Considera-se que a dança contribui diretamente com o desenvolvimento motor da criança, porém não fica restrita somente a essa especificidade, a partir da dança é possível explorar diversos aspectos para o desenvolvimento desta, como a dança como elemento da cultura, como arte, prazer, a dança na interdisciplinaridade, a dança para reconhecimento corporal, a dança como expressão, dentre outras possibilidades.

No intuito de dar visibilidade aos saberes das professoras de educação infantil sobre a dança e a relação destacada com o desenvolvimento motor, aprofundando as discussões sobre os dados apontados pelo software Iramutec, apresenta-se a seguir falas obtidas no questionário 
A dança e atividades musicais possibilitam que a criança desenvolva inúmeras habilidades alem de noções de lateralidade e espaço, também faz com que a criança amplie os conhecimentos sobre o próprio corpo. É uma forma de expressão muito valiosa que deve estar presente diariamente na Educação Infantil. (PROFESSORA H)

A dança desenvolve toda a coordenação motora. (PROFESSORA K)

Entretanto, com já descrito no decorrer deste estudo, o trabalho com a dança não deve ser limitado somente ao desenvolvimento motor, como já mencionado, a dança contribui no desenvolvimento da criança como um todo, "por ser a dança movimento, expressão, comunicação, linguagem humana básica e própria de nossa cultura, é essencial a inclusão dessa arte na Educação Infantil em busca da formação integral das crianças" (VARGAS, 2014, p.235).

Em contrapartida, uma das professoras diz que:

A dança na prática pedagógica favorece o reconhecimento das possibilidades corporais da criança, também favorece o desenvolvimento da coordenação motora ampla, exploração de posturas corporais, ampliação do controle sobre o corpo e seus movimentos, a criança por meio da dança expressa suas emoções e criatividade (PROFESSORA M)

Apesar de se encontrar referências a elementos psicomotores, a resposta da professora $\mathrm{M}$ mostrou um conhecimento mais amplo sobre a importância da dança, e as contribuições que ela possibilita para a criança pequena. Além da sua contribuição no desenvolvimento motor, ela cita que através da dança a criança pode expressar suas emoções e criatividade, e ter essa consciência já é um grande passo para desenvolver um trabalho pedagógico significativo através da dança, e também um ponto de partida para buscar adquirir mais saberes sobre a dança nas práticas pedagógicas e suas contribuições.

As especialistas ao serem questionadas sobre a dança e a relação desta prática com a aprendizagem, responderam:

Sim, muito importante. (ESPECIALISTA A)

Considero fundamental, deveria ser uma disciplina específica na escola. (ESPECIALISTA B) 
A partir das respostas, as especialistas demonstram considerara importância da dança no processo de ensino-aprendizagem das crianças desde bem pequenas. E se pensar uma disciplina específica de dança, ou de se ter momentos oportunos nas práticas dentro das escolas é muito importante, de modo a não se trabalhar a dança sucintamente, de forma rápida e solta.

Seguindo a análise das respostas, no questionamento referente a relação entre a dança e aprendizagem e as formas de integração entre elas, o software Iramuteq apresentou os seguintes dados (Figura 11):

FIGURA 11: Dança e aprendizagem

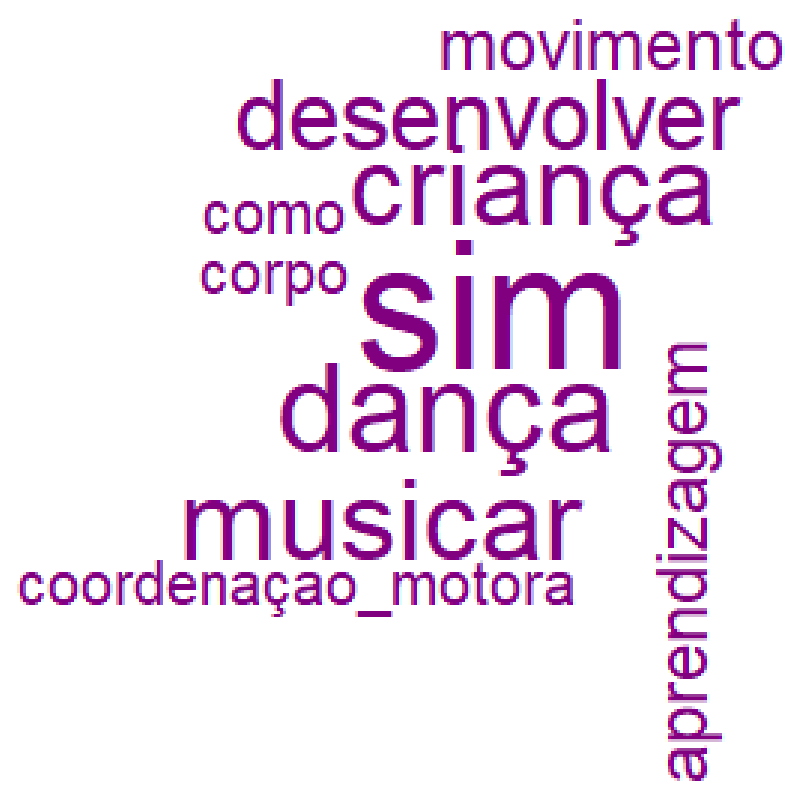

FONTE: Software Iramutec

Neste momento, é interessante perceber que a dança continua sendo reconhecida como contribuição para o desenvolvimento motor da criança. Ao observar a nuvem de palavras percebe-se que a palavra "sim" foi a que mais esteve nas respostas, isso indica que as professoras entendem que há relação entre a dança e a aprendizagem, porém quando se pensa na forma de integração entre elas, o que acaba sendo mencionado pelas professoras na maioria das vezes é a utilização da dança para o desenvolvimento motor.

No entanto dentre as palavras mais citadas, a "música" está presente. A música é uma grande aliada quando se trata de dança, sendo que ela possibilita um trabalho a partir da dança de modo a proporcionar para a criança momentos de grandes aprendizagens 
significativas. Porém, nas respostas das professoras a música e a dança foram relacionadas com o processo de memorização:

Sim. A musica é algo fácil de memorizar e muito mais gostoso pode ser utilizada como instrumento de fixação do que esta sendo ensinado. (PROFESSORA C)

Sim, através da dança a criança irá aprender brincando, tornando o seu aprendizado prazeroso. A criança irá associar o movimento com o ritmo da música, desenvolverá a criatividade ao pensar nos gestos e relacionar o tempo da música e os movimentos, desenvolve também a atenção, a memorização. (PROFESSORA G)

Recorremos aos escritos deste trabalho, cujos autores Barreto (2004), Marques (2012), Godoy (2011), entre outros, ressaltam que a dança não deve ser utilizada apenas como mera memorização de passos que já foram criados pelas professoras e transmitidos às crianças, de modo a fazer com que as crianças sigam apenas um padrão imposto. A criança precisa ser motivada a criar os seus passos, construindo a sua identidade na dança, entendemo e das também a importância da exploração sonora, de objetos, do corpo, da natureza, num processo de construção e representação.

Outro ponto mencionado nas respostas das professoras foi a contribuição da dança no processo da construção da imagem corporal.

Sim. Quando a criança dança ao mesmo tempo que desenvolve a coordenação motora, conhece o corpo, desenvolve a lateralidade, estimula a imaginação e entra em contato com o mundo da arte, além de poder expressar-se e interagir com os colegas facilitando a interação entre as crianças. Esses são alguns dos benefícios da dança na aprendizagem das crianças. (PROFESSORA H)

Sim. Quem dança tem mais facilidade de construir a imagem corporal. (PROFESSORA K)

As professoras $\mathrm{H}$ e $\mathrm{K}$ reconhecem a importância da dança na construção da imagem corporal da criança, na qual ela explora o seu corpo e movimentos que ele é capaz de realizar. Ter esse conhecimento é essencial para que se possa dar início ao egresso da dança nas práticas pedagógicas.

De acordo com Marques (2014, p.75): 
[...] As crianças que tem oportunidade expandir seus corpos, de correr, pular são bem diferentes daquelas que só ficam sentadinhas fazendo lição na mesinha. As primeiras, em geral, são crianças que percebem seu entorno de forma mais ampla, mais profunda e mais apurada e, portanto, estabelecem relações com os outros de maneira, provavelmente, mais significativa.

A dança possibilita que a criança construa sua imagem corporal, conhecendo seu corpo como um todo, bem como suas especificidades, logo, esta criança também poderá reconhecer e compreender o meio o qual ela está inserida com mais maturidade e criticidade. Deste modo, é muito importante que a criança tenha contato com a dança desde bem pequena, porém essa dança deve ser realizada com intencionalidade pedagógica, tendo como objetivo proporcionar para as crianças o reconhecimento de si, do outro, do meio, para além de coreografias prontas e apresentações escolares.

Retomando as orientações das DCNEIS, no que diz respeito as interações, é importante pensar a dança como contato consigo e com o outro, como espaço para mãos dadas, para corpos diferentes em tempos e ritmos diferentes, para meninos e meninas juntos... Para o reconhecimento das diversas culturas e suas danças, seus corpos e seus valores.

As profissionais especialistas em dança, quando indagadas sobre qual a importância da dança para a organização e o reconhecimento corporal da criança, elas apresentaram as seguintes respostas:

A dança é de grande importância para a criança. Assim como qualquer outra atividade ligada ao movimento. Antes de querer trabalhar qualquer outra atividade/conhecimento/conteúdo, a criança precisa se dar conta do que ela é quanto corpo. Se reconhecer corporalmente e espacialmente. Ter a consciência de que ela habita um corpo que pode mudar constantemente dentro de um espaço que também muda constantemente. Com a música associada ao movimento é possível fazer com que a criança dance naturalmente, explorando seu corpo, se (re)conhecendo através de atividades rítmicas e corporais de forma lúdica, sem intenções técnicas ou artísticas. A dança além de proporcionar o reconhecimento de si faz com que a criança reconheça o outro. (ESPECIALISTA A)

A dança proporciona vocabulário motor amplo, domínio de movimento, expressão corporal, musicalidade. (ESPECIALISTA B)

Ao analisarmos tais respostas percebemos a grande contribuição da dança para o reconhecimento corporal da criança, que desde bem pequena está em constante movimento, de modo que cada movimento se faz como grande descoberta para esta criança, oferecendo a 
oportunidade de conhecer o seu corpo como um todo bem como suas potencialidades e limitações. Segundo Souza (2016, p.46):

O movimento é inerente à criança e, ao longo do processo de desenvolvimento, seus gestos vão se tornando coesos e precisos. Mexer, apalpar, pegar, procurar, cair, levantar, pular e correr são ações decisivas para a criança se conhecer, identificar suas possibilidades, limitações, sensações e preferências, apropriando-se do corpo e das ações. É por meio do movimento que os pequenos conhecem o mundo que os cerca.

Por meio dos movimentos a criança constrói e identifica sua capacidade corporal e reconhece o meio no qual ela está inserida. É de fundamental importância que professoras que trabalham com crianças pequenas tenham essa compreensão sobre as práticas de dança, corpo e movimento, passando a refletir e a perceber que a dança vai muito além do que está posta na atualidade dentro das escolas vinculadas ao ensino de, ou a comemorações e/ou festivais.

\section{Dentre caminhos e possibilidades}

Tratar do corpo na escola ainda se constitui um grande desafio, muito caminhamos mas muito ainda temos que trilhar a fim de superar a dicotomia corpo - mente, a restrição dos movimentos, o controle sobre o corpo, os preconceitos de gênero em relação a dança, passando por questões que envolvem saúde física e mental, convivência, respeito e liberdade de expressão.

Quando a criança dança, ela conhece seu corpo, explora seus limites e suas habilidades, interage com o seu "eu" e com o "outro", inclusive tem contanto com músicas que lhes possibilitam acesso ao conhecimento de diversificadas culturas, agregando em sua aprendizagem.

Desse modo, se faz necessário repensar a efetivação do trabalho com a dança na Educação Infantil, em razão de que um grande ponto observado durante a realização deste trabalho, a partir dos estudos dos materiais teóricos, bem como no processo de obtenção dos dados, gerando uma grande inquietação, foi perceber que a maioria das professoras que trabalham com as crianças pequenas não compreendem tamanha possibilidade do trabalho com a dança, e que ela é grande aliada no processo de aprendizagem e desenvolvimento da criança. 
Ao analisarmos os saberes e os fazeres das professoras, é possível perceber a necessidade de ampliação da discussão sobre corpo e movimento na formação de professores. Propiciar reflexões teóricas, vivencias, debates e questionamentos que permitam olhar para si e para o outro, que permitam desnaturalizar práticas como vinculação da dança a apresentações muitas vezes massantes e sem sentido, em datas comemorativas. É fundamental trazer a problematização sobre o corpo e o movimento para o espaço formativo, seja em formação inicial ou continuada.

Que os corpos passem dos portões das instituições para fazer parte do cotidiano da Educação Infantil, que estes corpos para além de alimentados e higienizados, possam expressar sua potência, sua plasticidade, sua alegria. Que possamos dançar todos os ritmos, criar e experimentar, dançar junto e solto, buscando outros sentidos e outras possibilidades para a prática pedagógica na Educação Infantil.

\section{REFERÊNCIAS}

ALMEIDA, F. S. Que dança é essa?: uma proposta para a educação infantil. São Paulo: Summus, 2016.

BARRETO, D. Dança...:Ensino, sentidos e possibilidades na escola. Campinas, SP: Autores Associados, 2004.

BRASIL. Ministério da Educação. Secretaria de Educação. Base Nacional Comum

Curricular. Básica. Diretoria de Currículos e Educação Integral. Brasília: MEC, 2017. Ministério da Educação. Secretaria de Educação Básica. Diretrizes Curriculares Nacionais Gerais da Educação Básica/ Ministério da Educação. Secretaria de Educação Básica. Diretoria de Currículos e Educação Integral. - Brasília: MEC, SEB, DICEI, 2013.

CAPRI, F. S. A dança na Educação Infantil: um olhar para a prática pedagógica. In: CAMARGO, D.; SANTA CLARA, C. W. (Org.). Educar a criança do século XXI: outro olhar, novas possibilidades. Curitiba: InterSaberes, 2015. p. 284-299.

FINCO, D. Campos de experiência educativa e programação pedagógica na escola da infância. In: BARBOSA, M. C. S. ; FARIA, A. L. G.; FINCO, D. (Org.). Campos de experiências na escola da infância: contribuições italianas para inventar um currículo de educação infantil brasileiro. Campinas, SP: Edições Leitura Crítica, 2015. p. 276.

FOUCAULT, M. Vigiar e punir: história da violência nas prisões. Rio de Janeiro: Editora Vozes, 2007. 
GARCIA, C. M. O professor iniciante, a prática pedagógica e o sentido da experiência. Revista Brasileira de Pesquisa sobre formação docente. Belo Horizonte, v. 2, n. 3, p. 1149, ago./dez. 2010.

GARANHANI, M. C. Brincadeiras no espaço institucional da Educação Infantil: em discussão os espaços da natureza. In: CAMARGO, D.; SANTA CLARA, C. W. (Org.). Educar a criança do século XXI: outro olhar, novas possibilidades. Curitiba: InterSaberes, 2015. p. 178-197.

A Educação Física na escolarização da pequena infância. Pensar a Prática: Educação Física e Infância. Revista da Pós-Graduação da Faculdade de Educação Física Universidade Federal de Goiás. Goiás: UFG, vol5, p.106-122, jul./jun. 2002

O movimento da criança no contexto da Educação Infantil: reflexões com base nos estudos de Wallon. Contrapontos, Itajaí, v. 5, n. 1, p. 81-93, jan./abr. 2005.

GODOY, K. A. A criança e a dança na Educação Infantil. Caderno de formação: formação de professores didática dos conteúdos. São Paulo: Cultura Acadêmica, v.5, p. 20-28, 2011.

MARQUES, I. Corpos e danças na Educação Infantil. In: GOBBI, M. A.; PINAZZA, M. A. (Org.). Infância e suas Linguagens. São Paulo: Cortez, 2014.

MARQUES, I. A. Interações: crianças, dança e escola. São Paulo: Blucher, 2012.

SILVA, M. Complexidade da formação de professores: saberes teóricos e saberes práticos. São Paulo: Editora UNESP; São Paulo: Cultura Acadêmica, 2009. p. 114.

BUSS-SIMÃO, M. Experiências sensoriais, expressivas, corporais e de movimento nos campos de experiências da Base Nacional Comum Curricular para a Educação Infantil. Debates em Educação, Maceió, v. 8, n. 16, p. 184-205, jul./dez. 2016.

VARGAS, L. A. M. A dança com alma de criança. In: CUNHA, Susana Rangel Vieira da Cunha (Org.). As artes no universo infantil. Porto Alegre: Mediação, 2014. p. 238-266.

i Professora - Colégio Sagrado Coração de Jesus - Ponta Grossa PR. e-mail: patriciatabordadarosa@outlook.com ORCID http://orcid.org/0000-0001-5699-2836 Ponta Grossa- ParanáBrasil.

ii Doutora em Ciências da Educação (UNLP-AR), professora do departamento de Pedagogia da Universidade Estadual de Ponta Grossa - PR (UEPG). Pesquisadora do GEPEEDI - Grupo de estudos, pesquisa e extensão em Educação Infantil (UEPG). E-mail: camargo.daiana@ hotmail.com ORCID http://orcid.org/0000-00021931-5577 Ponta Grossa- Paraná- Brasil.

1 Para a liberação da pesquisa realizamos a solicitação junto à Secretaria Municipal de Educação, via protocolo do projeto da pesquisa e do termo de consentimento livre e esclarecido.

2 Optou-se em manter os dados do questionário tal como está escrito pelas participantes da pesquisa 